\title{
Antiobiotics without food
}

Published at www.cmaj.ca on Feb. 26

$\mathrm{W}$

hen I applied for an elective in social pediatrics in the Department of Pediatrics at the University of Toronto in Ontario, I had the naïve impression that I would be treating "underprivileged" families within the confines of a comfortable clinic at the Hospital for Sick Children.

Instead, I held infants in tiny, dark apartments because their parents could not afford electricity. I saw children with fetal alcohol syndrome and mothers struggling to make ends meet. I met adolescents who had survived rape, abuse and neglect at the hands of their own families. My eyes were opened once and for all to the effect of poverty and racial inequalities on the health of Canadian children.

I researched the statistics and was shocked to find that one in three Canadian children lives in poverty and that a high percentage of those live in Toronto. The rates of illiteracy and homelessness are astonishing, as are the effects of these conditions on a child's brain development.

Though the concept of experiencebased brain development was not entirely new to me, it does take on a whole new meaning when one imagines the possible implications of growing up hungry in an abusive household.

Over the course of my elective, I began to wonder: How can we expect children growing up in these conditions to become healthy, well-adjusted adults after such a start? How can we improve their life trajectory? How can we reach out to these children and families earlier on?

The lens through which I view patients and physician-patient relationships was forever altered. Never again will I advise a patient to take antibiotics with food, without wondering if they actually have food to eat at home, as one experience with an 18-year-old girl in a

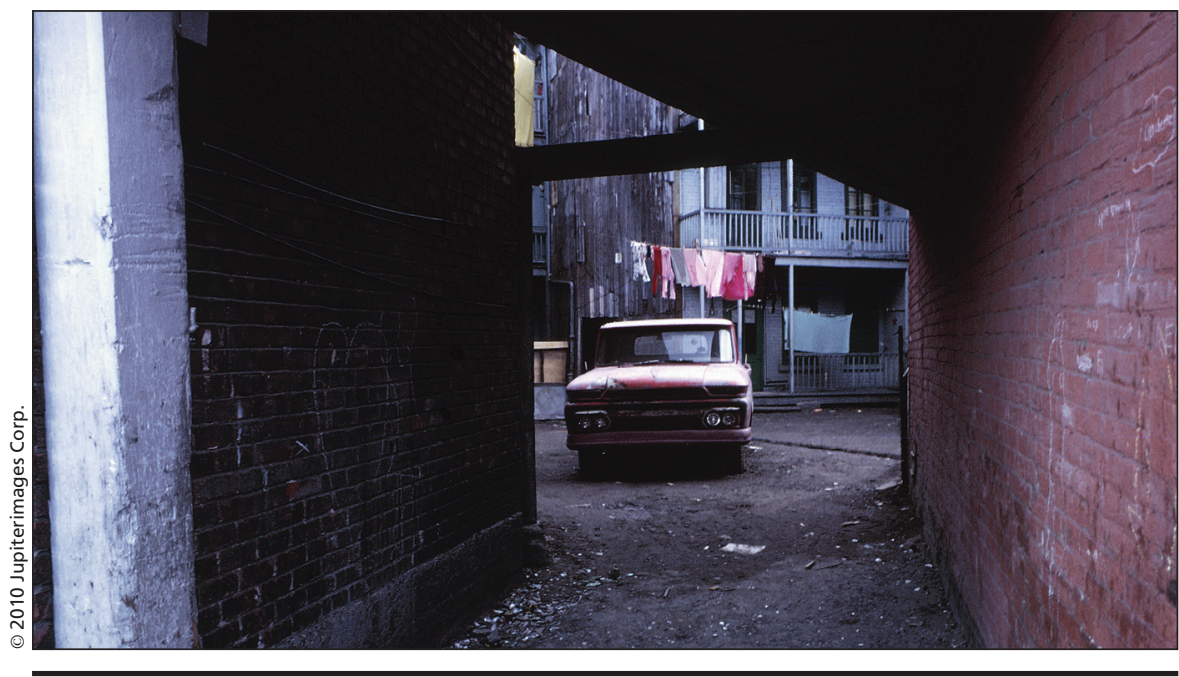

Living situations, income and family relationships have an impact on treatment plans and the therapeutic relationship, a medical student at McGill University in Montréal, Quebec, discovers during a social pediatrics elective.

group home taught me. Commuting on the subway, train and bus for three hours a day to participate in a Scarborough teen clinic gave me new-found empathy for the single mothers who travel with their children for downtown appointments.

Medical education often focuses on physicianship and whole-person care, but only rarely do most clinicians include social context in the "relevant" history. From now on, I will find it difficult to create a treatment plan for a patient without considering this information. Income, living situation and family relationships have a great impact on the success of treatment plans and the therapeutic relationship.

Calling my social pediatrics elective life-changing would not be an exaggeration. I certainly came away with an altered perspective on medicine and patients. The question I am left with is how to use this information to make a difference. Since my interests include both student leadership and medical education, I plan to spread awareness among my fellow medical students. But awareness is only a first step toward change.

As an aspiring pediatrician, I plan to become involved in public health projects during residency in hope that some concrete differences can be made for children.

I know that the problem of child poverty and its impact on child health is overwhelming; it will require a huge amount of social change at all levels to begin affecting the status quo. Just contemplating the notion can be intimidating. Yet, as the Irish politician Edmund Burke wrote: "Nobody made a bigger mistake than he who did nothing because he could only do a little." - S. Kate Amiel, Montréal, Que.

DOI:10.1503/cmaj.109-3173

$C M A J$ invites contributions to "Dispatch from the medical front," in which physicians and other health care providers offer eyewitness glimpses of medical frontiers, whether defined by location or intervention. Submissions, which must run a maximum 700 words, should be forwarded to: wayne .kondro@cmaj.ca 